\title{
FORMAS CLÍNICAS DA PARACOCCIDIOIDOMICOSE
}

\section{FORMAS GLINICAS DA PARACOCCIDIOIDOMICOSE}

Durante o "Segundo Encontro sobre Paracoccidioidomicose" realizado em Botucatu em 1983, foi criada uma comissão para propor uma classificação das formas clínicas da Paracoccidioidomicose integrada por Dra. Maria de Albornoz (Caracas, Venezuela), Dr. Gildo Del Negro (São Paulo, Brasil), Dr. Adhemar Fiorillo (Ribeirão Preto, Brasil), Dr. Alberto Londero (Santa Maria, Brasil), Dr. Ricardo Negroni (Buenos Aires, Argentina), Dr. Antar PadilhaGonçalves (Rio de Janeiro, Brasil) e Dra. Angela Restrepo (Medellin, Colombia), comissão esta presidida pelo Dr. Mário R. Montenegro (Botucatu, Brasil).

Terminado o Encontro a presidência enviou aos membros uma classificação semelhante : à proposta por Franco e Montenegro em Del Negro, G.; Lacaz, C. S. e Fiorillo, A. M., "Paracoccidioidomicose" (São Paulo, Sarvier/EDUSP, 1982), como base para as discussões.

Todos os membros da Comissão enviaram comentários e sugestões. Durante o "Coloquio Internacional sobre la Paracoccidioidomicosis" que foi realizado em Medellin, em Fevereiro de 1986, os membros da Comissão que estavam presentes com a colaboração de mais a Dra. Maria A. Shikanai-Yasuda (São Paulo, Brasil) e Marcello F. de Franco (Botucatu, Brasil), discutiram os comentários e sugestões e propuseram a seguinte classificação:

1. Paracoccidioidomicose Infecção

2. Paracoccidioidomícose Doença

2.1. Forma aguda ou subaguda (Tipo juvenil)

2.1.1. Grave

2.1.2. Moderada

2.2. Forma crônica (Tipo adulto)

2.2.1. Unifocal

Leve

Moderada

Grave

2.2.2. Multifocal

\author{
Leve \\ Moderada \\ Grave
}

3. Formas residuais ou sequelas

Caracterização das formas clínicas

1. Paracoccidioidomicose Infeç̧ão

Afeta indivíduos de ambos os sexos, aparentemente sadios, que residem ou residiram em zona endêmica e que tem reação intradérmica específica positiva. Neles não se observa depressão da resposta imune celular. Em alguns deles é possivel encontrar cicatrizes radiológicas pulmonares. Incluem-se também nesta forma casos de autópsia em que se encontram cicatrizes de lesōes especificas (com fungos ou seus fragmentos).

2. Paracoccidioidomicose Doença

2.1. Forma aglda ou subaguda (Tipo Juvenil)

Forma habitualmente severa de evolução rápida que afeta jovens de ambos os sexos e compromete preferencialmente o sistema monocítico-fagocitário. Os doentes, em geral, apresentam, depressão da resposta imune celular e aumento da produção de anticorpos específicos.

Ocorrem dois subtipos:

2.1.1. Grave - Se caracteriza por histó ria curta, instalação e progressão rápidas com deterioração grave do estado geral e diminuição da capacidade de trabalho. Compromete principalmente nódulos linfáticos, fígado, baço e medula óssea.

2.1.2. Moderada - Se caracteriza por instalação e progressão mais lentas que as de tipo grave; a deterioração do estado geral e da capacidade de trabalho é menor e costuma comprometer somente um sistema ou uma cadeia linfática.

\subsection{Forma crônica (Tipo Adulto)}

Se caracteriza por duração prolongada, instalação lenta e gradual com alteração progressiva do estado geral. Acomete principalmente 
indivíduos do sexo masculino de 30 ou mais anos. Pode ser leve, moderada ou grave. Aqui também se distinguem dois subtipos:

2.2.1. Unifocal - Se manifesta por sinais e sintomas referidos a um único órgão ou sistema como por exemplo os pulmões, as suprarenais, a pele, o sistema nervoso, etc. A imunidade celular está pouco deprimida ou conservada. Os anticorpos costumam estar presentes, porém, em níveis moderados.

2.2.2. Multifocal - Se caracteriza por sin. tomas e sinais referidos a mais de um órgão ou sistema como por exemplo pele, mucosas e pulmões, supra-renais e pulmões, etc. As alterações da resposta imune celular e humoral são variáveis.

\section{Formas residuais ou sequelas}

Se manifestam por sintomas e sinais relacionados com as sequelas cicatriciais de lesões ativas pregressas como enfisema pulmonar, estenose da laringe ou traquéia, etc.

\section{Comentáxios}

1. A classificação proposta é simples e deve ser feita com base nos dados da história clínica, do exame físico e da radiologia dos pulmões, de forma a que possa ser aplicada por qualquer médico com os meios habitualmente đisponiveis em seu consultório. A avaliação da resposta imune, se bem que não seja indispensável para a classificação, contribui para melhor compreensão da fisiopatogenia.

2. A realização de exames mais especializados poderá mostrar, especialmente nos casos da forma crônica unifocal, o comprometimento silencioso de outros órgãos ou sistemas. Nestes casos o clínico utilizará sua experiência para decidir se o caso deva ser enquadrado como uni ou multifocal.

Da mesma forma, a classificação de um caso de forma crônica como leve, moderado ou grave fica por conta dos critérios do clínico.

3. Alguns membros da Comissão consideram oportuno incluir casos de primo-infecção sintomática, caracterizados por processos pulmonares agudos ou subagudos ou por síndromes cutâneos cancriformes. Deve ser reconheci. do, no entanto, que sua caracterização clínica como primo-infecção é difícil.

4. A Comissão considera que a grande maioria dos casos se origina nos pulmões se bem que, em um momento dado da doença, o comprometimento đos pulmōes seja dificilmen. te demonstrável.

\section{CORRESPONDENCIA:}

Prof. MARIO RUBENS G. MONTENEGRO Fac. da Medicina de Botucatu (UNESP) Depto. de Patologia

18600 Botucatu, S. Paulo, BRASIL

Recebido para publicação em 5-4-86 